\title{
Assessment of Gingival Health Status among Patients with Fixed Orthodontic Appliance
}

\author{
Shahida R. Hussein ${ }^{1 *}$, Bayan A. Hassan² \\ ${ }^{1}$ Department of Dental Assistant, Erbil Medical Technical Institute, Erbil Polytechnic University, Erbil, Kurdistan Region, Iraq, ${ }^{2}$ Department of \\ Pedodontics, Orthodontic and Preventive, College of Dentistry, Hawler Medical University, Erbil, Kurdistan Region, Iraq
}

\section{${ }^{*}$ Corresponding author: \\ Shahida R. Hussein, \\ Department of Dental \\ Assistant, Erbil Medical \\ Technical Institute, Erbil \\ Polytechnique University, \\ Erbil, Kurdistan Region, Iraq. \\ E-mail: shahida.husain@ \\ epu.edu.iq}

Received: 10 June 2020

Accepted: 01 October 2020

Published: 30 June 2021

DOI

10.25156/pti.v11n1y2021.pp38-41

\section{A B S TR A C T}

Fixed orthodontic appliances corrupt plaque removal, proper oral hygiene, and gingival health so periodontal evaluation is important to be checked in every appointment. The aim of the present study was to assess gingival health among patients with a fixed orthodontic appliance. A clinical comparative study conducted on 25 patients with an aged ranged from 15 to 25 years. Clinical parameters included plaque index (PI), gingival index (GI), and bleeding on probing (BOP) were recorded at base line before starting orthodontic treatment and after 1 month of treatment. A double paired $t$-test was applied to the data collected for statistical analysis. The mean value of PI (1.11), GI (1.155), and BOP (0.600) scores was increased after placement of fixed orthodontic appliance, but with no statistically significant difference with base line for $\mathrm{PI}(P$-value $=0.596), \mathrm{GI}(P$-value $=0.355)$, and BOP $(P$-value $=0.256)$, respectively. Regarding age group, mean PI (1.46), GI (1.22), and BOP (0.875) were increased with increasing age, patients who age's $\geq 20$ showed statistical significant difference for gingival and plaque means $P$-value $=0.006$ and $P$-value $=0.03$ ) for $\geq 20$, respectively. The finding of this study had shown that patients with fixed orthodontic appliances had non-significant increase in the mean value of plaque, gingival, and BOP indices scores. All mean scores were increased with increasing age, but with non-significantly for BOP only.

Keywords: Age; Bleeding on probing; Fixed orthodontic appliance; Gingival index; Plaque index

\section{INTRODUCTION}

The effect of orthodontic therapy on periodontal status has been analyzed; small detrimental effects to the periodontium were highlighted (Bollen et al., 2008). The orthodontic appliance and crowding itself gives the plaque more retentive areas to accumulate on, which combined with lack of proper oral hygiene procedures affects the periodontal tissues in a destructive manner (Kitada et al., 2009); (Firas et al., 2020). Bogren et al. suggested that the accumulation of microbial plaque on teeth is a direct cause of gingivitis and periodontitis (Bogren et al., 2007). Areas around metal brackets are difficult to clean and are enhance the adhesion of bacteria and debris, whereas, in the case of orthodontic bands, biofilm formation occurs mostly at the gingival margin, leading to periodontal inflammation (Demling et al., 2009), (Mei et al., 2017).

Daily tooth brushing and the natural cleansing action of saliva in the oral cavity are generally insufficient for removing the biofilm. Furthermore, introducing foreign objects, such as orthodontic appliances, can alter the normal functioning of the oral cavity. Saliva plays a key role in maintaining oral health by performing several functions such as lubrication and antimicrobial activity (Humphrey and Williamson, 2001).

Placement of orthodontic brackets and bands usually makes proper plaque removal more difficult. Increases in food deposits and dental plaque often lead to enamel demineralization and gingival change if patients cannot maintain good oral hygiene (Tufekci et al., 2011).

Most studies reporting on gingival changes after bracket placement suggested only temporary reversible periodontal changes (Gomes et al., 2007).

Hence, aim of the present study was to assess gingival health among patients with a fixed orthodontic appliance.

\section{SUBJECTS AND METHODS}

The study sample consisted of 25 patients aged between 15 and 25 years old of both gender with different malocclusion need to be treated by fixed orthodontic appliance, the orthodontic appliance for the present study consisted primarily of four stainless steel Buccal tube (Ortho-Cast M-Series, non-convertible, DENTARUM, Ispringen, 
Germany), and 20 stainless steel brackets (equilibrium ${ }^{\circledR} 2$ "Roth 0.022", DENTARUM Ispringen, Germany) upper and lower NiTi archwires (Super elastic, 0.12, 0.14, 0.16, 0.18 rematitan ${ }^{\circledR}$ "LITE” ideal arch, round, DENTARUM, Ispringen, Germany).

All of the participants were systematically healthy with different mal occlusion to the college of dentistry at Hawler Medical University seeking for orthodontic treatment. (Hamad and Abdulla, 2018) They were randomly selected and examined after taking permission from the patient/ parent. Patients with chronic systemic illness, on any longterm oral medication, with recent use of antibiotics, with the previous orthodontic treatment and who were not interested to participate in the study were excluded. The procedure was carried out before starting orthodontic treatment and subsequently, 1 month after the placement of the appliance. Before placement of the orthodontic appliance, the patients underwent complete oral examination and oral hygiene maintenance instruction was given to the patient before and during fixed orthodontic appliance orally and in written form. The appliance was placed by orthodontic professionals from the department of orthodontics.

The clinical examinations were performed in the orthodontic clinics of the college of dentistry/Hawler Medical University. Plaque index (PI) according to Silness and Löe (Silness and Löe, 1964), gingival index (GI) according to Löe and Silness (Löe and Silness, 1963), and bleeding on probing (BOP) according to (Almiñana-Pastor et al, 2017) in which BOP was considered positive when bleeding was observed 20 seconds after probing. Ramfjord index (Ramfjord, 1959) was used for the examination of 6 teeth included upper right $1^{\text {st }}$ molar, upper left central incisor, and upper left $1^{\text {st }}$ premolar, lower right $1^{\text {st }}$ premolar, and central incisor and lower left $1^{\text {st }}$ molar. A patient who had $<20$ teeth was excluded from the study according to Hussien (Husse, 2011).

PI, GI, and BOP were clinically measured 2 weeks before the placement of fixed orthodontic appliances and 4 weeks after the placement of orthodontic treatment. Using straight explorer for PI and Williams graduated periodontal probe for GI and BOP. The statistical analysis of the data was carried out using (SPSS) version 22. This includes:

1. Descriptive statistics (mean, minimum, maximum standard deviation, and degree of significance)

2. A paired sample $t$-test was used to compare two groups of the mean.

\section{RESULTS}

Table 1 showed that the mean value of PI (1.11) was increased after placement of fixed orthodontic appliance but with non-statistical significant difference with base line before therapy $(P=0.596)$.

Table 2 showed that mean value of gingiva index (1.155) was increased after placement of fixed orthodontic appliance with non-significant statistical difference with base line before therapy $(P=0.355)$.

Table 3 revealed that mean value of BOP (0.666) was increased after placement of fixed orthodontic $(P=0.256)$.

Table 4 showed that mean value of PI (1.46), GI (1.22), and BOP $(0.875)$ increased with increasing age of patients who ages equal or more than 20 after placing fixed orthodontic appliance with statistical significant difference for both gingival and plaque means $(P=0.006$ and $P=0.03)$, respectively, for $\geq 20$.

\section{DISCUSSION}

Fixed orthodontic appliances induce mechanical plaque traps and impair plaque removal, proper oral hygiene, and gingival health. (Anhoury et al., 2002) Gingivitis can be develop in patients who do not institute proper oral hygiene measures and can become quite profound in 21 days. Patients often exhibit increased plaque accumulation, gingival hypertrophy, bleeding, and calculus formation during orthodontic treatment, (Turkkahraman et al., 2005).

Results of the present study revealed that the mean value of plaque and gingival indices for patients after placement of fixed orthodontic appliance was more than before appliance with no statistically significant difference. In other studies, the periodontal index (PI, GI, gingival bleeding index, and

Table 1: Mean PI before and after placing fixed orthodontic
appliance
\begin{tabular}{|lcccccc|}
\hline PI & Mean & \pm SD & Min & Max & Df & P-value \\
\hline Before ortho & 0.999 & 0.298 & 0.50 & 1.54 & 24 & 0.596 \\
After ortho & 1.111 & 0.383 & 0.33 & 1.83 & & \\
\hline
\end{tabular}

PI: Plaque index

Table 2: Mean GI before and after placing fixed orthodontic appliance

\begin{tabular}{lcccccc}
\hline GI & Mean & $\pm S D$ & Min & Max & Df & $P$-value \\
\hline Before ortho & 1.051 & 0.391 & 0.13 & 1.71 & 14 & 0.355 \\
After ortho & 1.155 & 0.275 & 0.59 & 1.66 & & \\
\hline
\end{tabular}

Gl: Gingival index

Table 3: Mean BOP before and after placing of fixed orthodontic appliance

\begin{tabular}{lcccccc} 
Bleeding index & Mean & $\pm S D$ & Min & Max & Df & $P$-value \\
\hline Before ortho & 0.440 & 0.5061 & 00 & 1 & 24 & 0.256 \\
After ortho & 0.6000 & 0.500 & 00 & 1 & &
\end{tabular}

BOP: Bleeding on probing 
Table 4: Mean plaque, gingival, and BOP indices before and after placing fixed orthodontic appliance in relation to age group

\begin{tabular}{|c|c|c|c|c|c|c|c|c|}
\hline$\overline{P I}$ & $\begin{array}{c}15-20 \\
\text { mean } \pm S D\end{array}$ & $\begin{array}{c}\geq 20 \\
\text { mean } \pm \text { SD }\end{array}$ & GI & $\begin{array}{c}15-20 \\
\text { mean } \pm S D\end{array}$ & $\begin{array}{c}\geq 20 \\
\text { mean } \pm \text { SD }\end{array}$ & BOP index & $\begin{array}{c}15-20 \\
\text { mean } \pm S D\end{array}$ & $\begin{array}{c}\geq 20 \\
\text { mean } \pm S D\end{array}$ \\
\hline Befor & $0.983 \pm 0.311$ & $1.03 \pm 0.285$ & Sefore & $1.06 \pm 0.44$ & $1.00 \pm 0.232$ & Bef & $0.4076 \pm .124$ & $0.375 \pm 0.517$ \\
\hline After ortho & $0.980 \pm 0.26622$ & $1.46 \pm 0.431$ & After ortho & $1.15 \pm 0.324$ & $1.22 \pm 0.149$ & After ortho & $0.41 \pm 0.124$ & $0.875 \pm 0.353$ \\
\hline P-value & $0.333 \mathrm{Df}=16$ & ${ }^{*} 0.006 \mathrm{Df}=7$ & P-value & $0.872 \mathrm{Df}=16$ & ${ }^{*} 0.03 \mathrm{Df}=7$ & P-value & $0.832 \mathrm{Df}=16$ & $0.482 \mathrm{Df}=7$ \\
\hline
\end{tabular}

PI: Plaque index, GI: Gingival index, BOP: Bleeding on probing

probing pocket depth) and microbiological parameters were determined before appliance placement and 1, 3, and 6 months after the beginning of treatment. The results described an increase in all clinical and microbiological parameters after appliance placement; and the maximum values were obtained after 3 months (Ristic et al., 2007). Furthermore, other studies who recorded plaque and gingival indices criteria in 3-time points before bonding ( $1^{\text {st }}$ visit), 2 weeks after bonding ( $2^{\text {nd }}$ visit) and 4 weeks after bonding ( $3^{\text {rd }}$ visit). All of these previous studies showed increased mean plaque and gingival indices after the placement of fixed orthodontic appliance (LaraCarrillo et al., 2010), (Doi et al., 2016), (Alasadi and Qasim, 2018), (Şincar and Leață, 2018). The sudden impact of pain through the first period which led to a change in the form of the food to a softer and less fibrous composition (Al Jawad, 2011). Addition of numerous components of the fixed orthodontic appliance (brackets and auxiliaries) that increase the difficulty of the conventional oral hygiene practices (Mount and Hume, 2005), which led to rapid and effective plaque formation. Plaque bacteria which considered the main factor in increasing gingival inflammation (Marsh et al., 2017).

The present study showed that there was an increase in the mean of BOP after placement of orthodontic appliance but without significant difference. The present study finds that all clinical parameters of PI, GI, and BOP were increased with increasing age after placement of fixed orthodontic appliance and there was significant difference for age $\geq 20$ years for both plaque and gingival indices. This finding is in agreement with other studies (Marsh et al., 2017) who perform their study on age (14-26) years and were in contrast with Nsour, 2013. On the other hand, the increase of visible inflammation and gingival recession among young adults was found statistically significant after treatment whereas the average visible plaque and inflammation values of the adolescents proved to be statistically significant after treatment who perform their study on age (12-17) and (18-32) (Karacaoglu et al., 2016).

\section{CONCLUSION}

The finding of this study had shown that patients with fixed orthodontic appliances had an increase in the mean value of PI, GI, and BOP scores but with non-statistically significant differences for all clinical parameters. Furthermore, all clinical scores were increased with age after placement of fixed orthodontic appliances but with non-statistically significant differences for BOP only.

\section{REFERENCES}

Al Jawad, F. A. 2011. An Investigation of the Early Effects of Fixed Orthodontic Treatment on Dietary Intake and Body Weight in Adolescent Patients. United Kingdom, Queen Mary's School of Medicine and Dentistry/University of London, PhD Thesis Dissertation.

Alasadi, A. Z. and A. A. Qasim. 2018. Early impact of fixed orthodontic therapy on gingival health status in relation to weight status. J. Baghdad Coll. Dent. 30(4): 2731.

Almiñana-Pastor, P. J., M. Segarra-Vidal, A. López-Roldán and M. Francisco. 2017. Alpiste-lllueca 3: A controlled clinical study of periodontal health in anticoagulated patients: Assessment of bleeding on probing. J. Clin. Exp. Dent. 9(12): e1431-e1438.

Anhoury, P., D. Nathanson, C. V. Hughes, S. Socransky, M. Feres and L. L. Chou. 2002. Microbial profile on metallic and ceramic bracket materials. Angle Orthod. 72: 338-343.

Bogren, A., R. P. Teles, G. Torresyap, A. D. Haffajee, S. S. Socransky and J. L. Wennström. 2007. Clinical and microbiologic changes associated with the combined use of a powered toothbrush and a triclosan/copolymer dentifrice: A 3-year prospective study. J. Periodontol. 78(9): 1708-1717.

Bollen, A. M., J. Cunha-Cruz, D. W. Bakko, G. J. Huang and P. P. Hujoel. 2008. The effects of orthodontic therapy on periodontal health: A systematic review of controlled evidence. J. Am. Dent. Assoc. 139(4): 413-422.

Demling, A., W. Heuer, C. Elter, T. Heidenblut, F. W. Bach, R. Schwestka-Polly and M. Stiesch-Scholz. 2009. Analysis of supra- and subgingival long-term biofilm formation on orthodontic bands. Eur. J. Orthod. 31: 202-206.

Doi, T., D. Hinode, H. Nakae, M. Yoshioka, M. Matsuyama, H. Iga and Y. Fukushima. 2016. Relationship between chewing behavior and oral conditions in elementary school children based on the "chewing 30" program: An intervention study. J. Dent. Health. 66: 438-444.

Firas, K. I., K. I. Zacaria, A. F. Rabah and L. Hu. 2020. Periodontal parameters in adult patients with clear aligners orthodontics treatment versus three other types of brackets: A cross-sectional study. J. Orthod. Sci. 9: 4.

Gomes, S. C., C. C. Varela and S. L. da Veiga. 2007. Periodontal conditions in subjects following orthodontic therapy. A preliminary study. Eur. J. Orthod. 29: 477-481.

Hamad, D. K. and B. Abdulla. 2018. Evaluation of salivary nickle, chromuim and iron ions in patients treated with fixed orthodontic appliance in vivo study. EDJ. 1(2): 15.

Humphrey, S. P. and R. T. Williamson. 2001. A review of saliva: Normal composition, flow, and function. J. Prosthet. Dent. 85: 162-169. 
Husse, H. S. R. 2011. Gingival health status and oral hygiene among patients attending health centers aged (20-80) years in Erbil city. Zanco J. Med. Sci. 15(1): 71-79.

Karacaoglu, F., C. Gazioglu, S. Akkaya and M. Akkaya. 2016. Are the effects of fixed orthodontic treatment on gingival health similar in adolescents and young adults? J. Biomed. Sci. 6: 1.

Kitada, K., A. De Toledo and T. Oho. 2009. Increase in detectable opportunistic bacteria in the oral cavity of orthodontic patients. Int. J. Dent. Hyg. 7: 121-125.

Lara-Carrillo, E., N. M. Montiel-Bastida, L. Snchez-Pérez and J. Alans-Tavira. 2010. Changes in the oral environment during four stages of orthodontic treatment. Korean J. Orthod. 40: 95-105.

Löe, H. and Silness, J. 1963. Periodontal disease in pregnancy. I. Prevalence and severity. Acta Odontol. Scand. 21: 533-551.

Marsh, P., M. Lewis, H. Rogers, D. Williams and M. Wilson. 2017. Oral Microbiology. $6^{\text {th }}$ ed. Churchill Livingstone, United Kingdom.

Mei, L., J. Chieng, C. Wong, G. Benic and M. Farella. 2017. Factors affecting dental biofilm in patients wearing fixed orthodontic appliances. Prog. Orthod. 18: 4.

Mount, G. J. and W. R. Hume. 2005. Preservation and Restoration of Tooth Structure. $2^{\text {nd }}$ ed. Knowledge Books and Software, Queensland.
Nsour, H. F. 2013. Short term effect of fixed orthodontic applaince on the periodontal health. Pak. Oral Dent. J. 33(2): 318-320.

Ramfjord, S. P. 1959. Indices for prevelance and incidence of periodontal disease. J. Periodontal. 30: 51-59.

Ristic, M., M. V. Svabic, M. Sasic and O. Zelic. 2007. Clinical and microbiological effects of fixed orthodontic appliances on periodontal tissues in adolescents. Orthod. Craniofac. Res. 10(4): 187-195.

Silness, J. and Löe, H. 1964. Periodontal disease in pregnancy. II. Correlation between oral hygiene and periodontal condition Acta Odontol. Scand. 22: 121-135.

Şincar, D.C. and R. Leaţă. 2018. Gingival study of periodontal parameters during orthodontic treatment. Rom. J. Oral Rehabil. 10(2).

Tufekci, E., J. S. Dixon, J. C. Gunsolley and S. J. Lindauer. 2011. Prevalence of white spot lesions during orthodontic treatment with fixed appliances. Angle Orthod. 81(2): 206-210.

Turkkahraman, H., M. O. Sayin, F. Y. Bozkurt, Z. Yetkin, S. Kaya and S. Onal. 2005. Archwire ligation techniques, microbial colonization, and periodontal status in orthodontically treated patients. Angle Orthod. 75: 231-236. 